JBB/Vol.2 Issue 1

\title{
Pharmacokinetic Evaluation of Metolazone Tablets using Healthy Human Volunteers
}

\author{
Basvan Babu*, Selvadurai Muralidharan, \\ Subramaniya Nainar Meyyanathan and Bhojraj Suresh
}

Department of Pharmaceutical Analysis, J.S.S.College of Pharmacy, (Off Campus of JSS University, Mysore) Ootacamund, Rocklands, Ooty

\begin{abstract}
A sensitive and reproducible high performance liquid chromatography (HPLC) method has been developed and validated for the quantification of metolazone in human plasma, after solid phase extraction (SPE). A Good resolution was achieved on a reverse-phase LichroCART Purospher ${ }^{\circledR} \mathrm{C}_{18}$ column using the mobile phase acetonitrile- $0.5 \%$ triethylamine $(35: 65)$ in isocratic elution with a total run time of $15 \mathrm{~min}$. The analyte, metolazone, was detected by using high performance liquid chromatography with the support of photo diode array detector. Limit of detection and Lower limit of quantification was found to be 1 and $2.5 \mathrm{ng} / \mathrm{mL}$. The present method was successfully applied in the pharmacokinetic study of metolazone in human plasma.
\end{abstract}

Keywords: Metolazone; Bioavailability studies; Pharmacokinetic evaluvation

\section{Introduction}

This work deals with the studies carried out by the writer in this laboratory for the past one year on the development of analytical method used for the estimation of Metolazone in biological fluids and Bioequivalence studies on Metolazone tablets. Metolazone is a diuretic/saluretic/antihypertensive drug of the quinazoline class. The chemical name is 7-chloro-1,2,3,4tetrahydro-2-methyl-3-(2-meth yl phen yl)-4-oxo-6quinazolinesulfonamide. Metolazone is a quinazoline diuretic, with properties generally similar to the thiazide diuretics. The actions of Metolazone result from interference with the renal tubular mechanism of electrolyte reabsorption. Metolazone acts primarily to inhibit sodium reabsorption at the cortical diluting site and to a lesser extent in the proximal convoluted tubule. Sodium and chloride ions are excreted in approximately equivalent amounts. The increased delivery of sodium to the distal tubular exchange site results in increased potassium excretion. Metolazone does not inhibit carbonic anhydrase. A proximal action of Metolazone has been shown in humans by increased excretion of phosphate and magnesium ions and by a markedly increased fractional excretion of sodium in patients with severely compromised glomerular filtration. This action has been demonstrated in animals by micropuncture studies. The antihypertensive mechanism of action of Metolazone is not fully understood but is presumed to be related to its saluretic and diuretic properties (wikipedia.com). Only limited methods have been reported for HPLC and LC-MS (Brodie et al., 1981; Farthing et al., 1990; Farthing et al., 1994; Wei et al., 2007; Jadhav et al., 2009; Guidance for Industry Bioanalytical Method Validation. U.S, 2001; Guidance for Industry, Statistical Approaches in Establishing Bioequivalence. U.S, 2001). Our aim is to develop a new and sensitive bioanalytical method.

\section{Experimental}

\section{Reagents and materials}

Working standard of Metolazone with $99.86 \%$ purity was obtained from German Remedies Ltd., Mumbai, India. Celecoxib (purity 99.38\%) working standard was obtained from Cadila Health Care Ltd., Ahmedabad, India). Acetonitrile (HPLC grade), obtained from Qualigens Fine Chemicals, Mumbai and potassium dihydrogen ortho phosphate, ortho phosphoric acid, methanol, and trichloroacetic acid (all analytical grade reagent) were purchased from S.D. Fine Chem. Ltd., Mumbai. In house mill Q water was used throughout the study. Fresh frozen human plasma used in the method development was obtained from the Vijay Hospital, Ooty, and was stored at $-70 \pm 2^{\circ} \mathrm{C}$ until required.

\section{Instrumentation}

The HPLC system consisted of a HPLC 10 AT-VP (Shimadzu Ltd., Japan), Manual injector port with $100 \mu \mathrm{L}$ loop (Rheodyne, USA) and UV detector (Shimadzu Ltd., Japan). The wavelength of the detector was set at $225 \mathrm{~nm}$. Detector output was quantified on CLASS VP (Version 6.01) chromatography software. Separation was carried out on a LichroCART Purospher ${ }^{\circledR} \mathrm{C}_{18}$, $(250 \mathrm{~mm} \times 4.6 \mathrm{~mm}, 5 \mu \mathrm{m})$, Japan, using mixture of $0.5 \%$ triethyl amine ( $\mathrm{pH} 3.5)$ and acetonitrile $(65: 35, \mathrm{v} / \mathrm{v})$ as a mobile phase, at a flow rate of $1 \mathrm{~mL} / \mathrm{min}$. Total analysis time was $15 \mathrm{~min}$. All analysis was performed at room temperature.

\section{Preparation of calibration standard and quality control stan- dards}

Stock solutions of metolazone and celecoxib (I.S) $(1 \mathrm{mg} / \mathrm{ml})$ were prepared in a mixture of water and acetonitrile $(1: 1 \mathrm{v} / \mathrm{v})$ and stored at $8^{\circ} \mathrm{C}$. The stock solution of metolazone was further diluted with the mixture of water and acetonitrile to give series of standard solutions. Galibration standard of metolazone (2.5, 5.0, $10.0,25.0,50.0,75.0,100.0,250.0$ and $500.0 \mathrm{ng} / \mathrm{ml}$ ) were prepared by spiking appropriate amount of the standard solution in blank plasma. Lowest quality control standards (LQC), median quality control standards (MQC) \& highest quality control stan*Corresponding author: Basvan Babu, Department of Pharmaceuti-
cal Analysis, J.S.S.College of pharmacy, Tamilnadu, India, Tel: +91-423-
2443393; Fax: +91-423-2442937; E-mail: thammababu@yahoo.co.in

Received December 29, 2009; Accepted January 21, 2010; Published January 22, 2010

Citation: Babu B, Muralidharan S, Meyyanathan SN, Suresh B (2010) Pharmacokinetic Evaluation of Metolazone Tablets using Healthy Human Volunteers. J Bioequiv Availab 2: 015-017. doi:10.4172/jbb.1000024

Copyright: (c) 2010 Babu B, et al. This is an open-access article distributed under the terms of the Creative Commons Attribution License, which permits unrestricted use, distribution, and reproduction in any medium, provided the original author and source are credited. 
Citation: Babu B, Muralidharan S, Meyyanathan SN, Suresh B (2010) Pharmacokinetic Evaluation of Metolazone Tablets using Healthy Human Volunteers. J Bioequiv Availab 2: 015-017. doi:10.4172/jbb.1000024

dards (HQC) were prepared by spiking drup free plasma with metolazone to give solutions containing 6.0, 50.0, and 500.0, $\mathrm{ng} / \mathrm{mL}$, respectively. They were stored at $-20 \pm 2{ }^{\circ} \mathrm{C}$ till analysed.

\section{Sample preparation with SPE}

To $0.5 \mathrm{ml}$ plasma sample containing metolazone (calibration standard $), 0.5 \mathrm{ml}$ of internal standard $(1.0 \mu \mathrm{g} / \mathrm{ml})$ was added and vortexed. Phenomenex Strata C18-E SPE cartridge was conditioned with acetonitrile and water sequently. The above conditioned cartridge $1 \mathrm{~mL}$ of sample solution was added.The cartridge was washed with water. The drug and internal standard was eluted from the cartridge using $1.0 \mathrm{~mL}$ of mobile phase. None of the drug free plasma samples studied in this assay yield endogenous interference at these retention times (Figure 1). We have performed with other methods such as Protien precipitation and Liquid Liquid extraction methods among these methods SPE extraction was found to be more precise $(98.28 \%$ recovery) results.

\section{Results and Discussion}

\section{Selectivity/sensitivity}

Selectivity of the method described was investigated by screening six different batches of human blank plasma. Under the proposed assay condition internal standard and metolazone had a retention time of 7.97 and $10.36 \mathrm{~min}$, respectively, rest of the peaks were due to the plasma components. Metolazone and internal standard were very well resolved under the proposed chromatographic conditions. None of the drug free plasma samples studied in this assay yield endogenous interference at these retention times (Figure 2).

\section{Accuracy and precision}

The mean percent accuracy of the proposed method was found to be $98.37 \%$. Intra day precision for metolazone was $5.75 \pm 0.38$, $49.19 \pm 0.17,498.35 \pm 0.87$ for the spiked concentration at 6.0 , 50.0 and $500.0 \mathrm{ng} / \mathrm{mL}$ respectively. Inter day precision for metolazone was $6.1 \pm 0.21,49.39 \pm$ and $499.97 \pm 0.32$ for the spiked concentration at 6.0, 50.0 and $500.0 \mathrm{ng} / \mathrm{mL}$, respectively (Table 1).

\section{Linearity}

The linearity study was carried out on seven different concen-

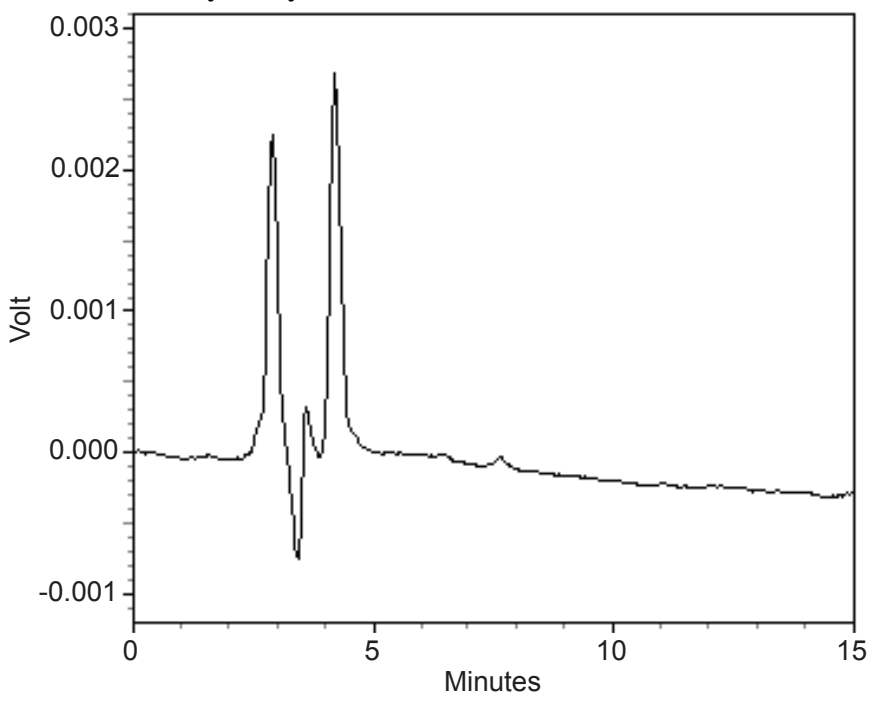

Figure 1: Blank sample chromatogram.

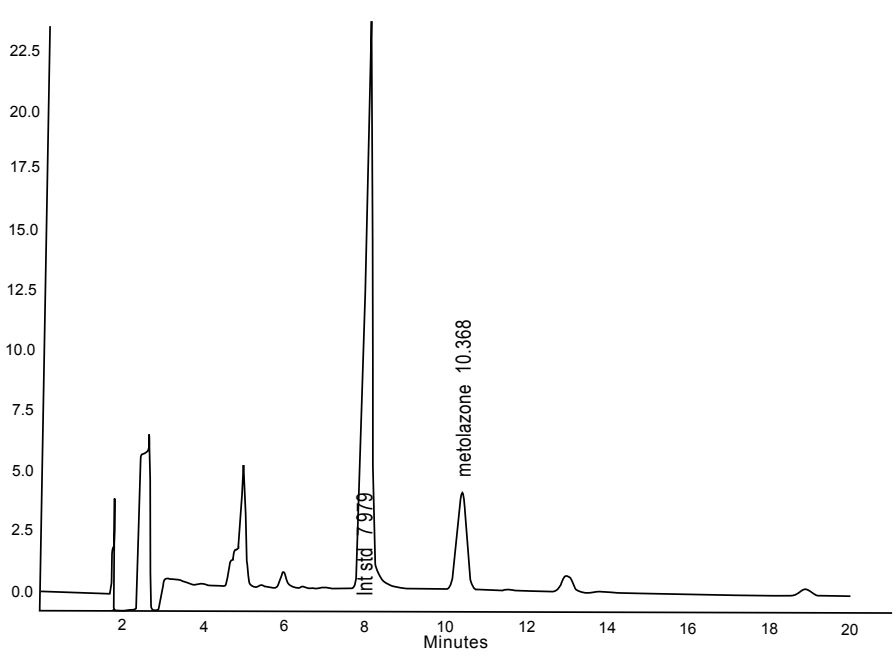

Figure 2: Sample Chromatogram.

\begin{tabular}{|l|l|l|l|}
\hline $\begin{array}{l}\text { Sample } \\
\text { concentration } \\
(\mathrm{ng} / \mathrm{mL}) \mathrm{n}=5)\end{array}$ & $\begin{array}{l}\text { Concentration } \\
\text { found } \\
(\mathrm{mean} \pm \text { S.D. }) \\
(\mathrm{ng} / \mathrm{mL})\end{array}$ & $\% \mathrm{CV}$ & $\%$ Accuracy \\
\hline 6.0 & $5.82 \pm 0.43$ & 7.45 & 97.13 \\
\hline 50.0 & $49.85 \pm 1.48$ & 2.98 & 99.71 \\
\hline 500.0 & $491.35 \pm 13.16$ & 2.67 & 98.27 \\
\hline
\end{tabular}

Table 1: Accuracy and Precision.

\begin{tabular}{|c|c|}
\hline Concentration $(\mathrm{ng} / \mathrm{mL})$ & Response Factor \\
\hline 2.5 & 0.03 \\
\hline 5.0 & 0.06 \\
\hline 10.0 & 0.10 \\
\hline 25.0 & 0.28 \\
\hline 50.0 & 0.49 \\
\hline 75.0 & 0.72 \\
\hline 100.0 & 1.06 \\
\hline 250.0 & 2.78 \\
\hline
\end{tabular}

Table 2: Calibration curve of metolazone.

tration of metolazone were analysed (2.5, 5.0, 10.0, 25.0, 50.0, $75.0,100.0,250.0$ and $500 \mathrm{ng} / \mathrm{mL}$ ). The peak area response was linear over the concentration range studied. Each experiment at all concentration was repeated three times on three separate days to obtain the calibration data. The coefficient of correlation ' $r 2$ ' was found to be 0.9978 (Table 2 and Figure 3).

\section{Recovery}

The mean extraction recoveries of metolazone determined over the concentration of $6.0,50.0$ and $500.0 \mathrm{ng} / \mathrm{ml}$ were $98.87 \%$, $99.03 \%$ and $99.94 \%$.

\section{Stability study}

Short-term and long-term stock solution stability studies evaluated, which proved no significant deviation from normal value when stored at $4^{\circ} \mathrm{C}$. The stability of metolazone in plasma was determined by measuring concentration change in quality control samples over time. Stability was tested by subjecting the quality controls to three freeze-thaw cycles and compared with freshly prepared quality control samples. The mean concentration of metolazone in quality control samples did not change 


\section{Journal of Bioequivalence \& Bioavailability - Open Access \\ JBB/Vol.2 Issue 1}

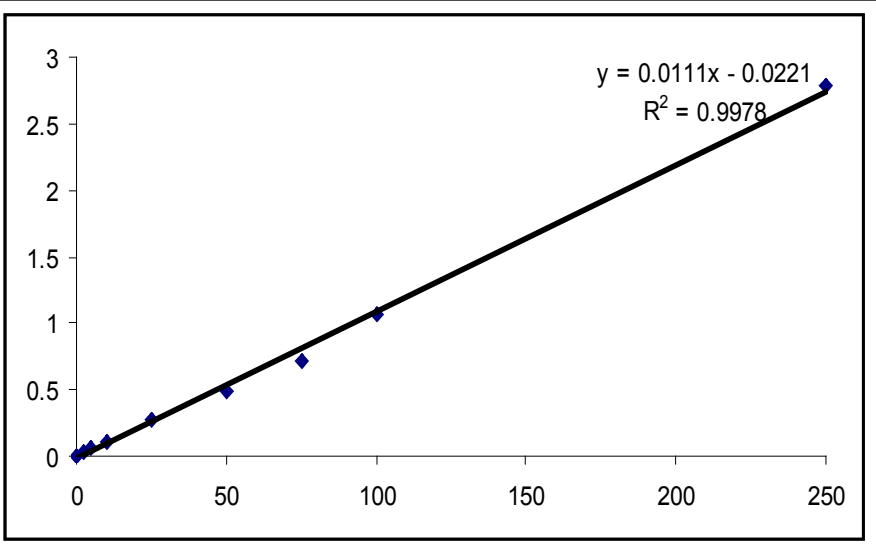

Figure 3: Calibration Curve of Metolazone.

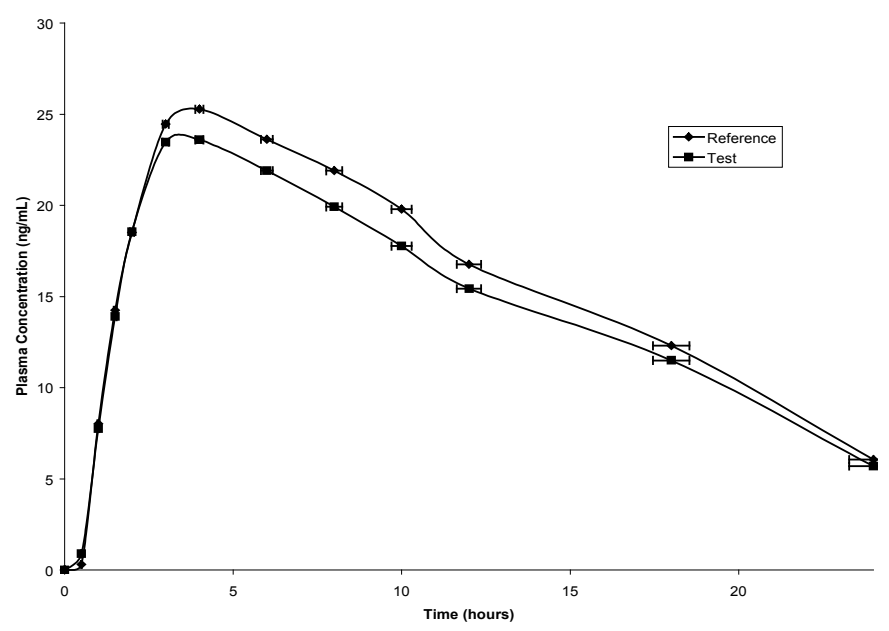

Figure 4: Mean plasma concentration.

\begin{tabular}{|c|c|c|}
\hline $\begin{array}{c}\text { Sample concentration } \\
(\mathrm{ng} / \mathrm{mL})(\mathrm{n}=5)\end{array}$ & $\begin{array}{c}\text { Concentration } \\
\text { found } \\
(\mathrm{mean} \pm \mathrm{S} . \mathrm{D} .) \\
(\mathrm{ng} / \mathrm{mL})\end{array}$ & \\
\hline Stock solution stability $(6$ & $5.96 \pm 0.07$ & 1.18 \\
h, 15,30days) & $50.31 \pm 0.62$ & 1.24 \\
6.0 & $499.69 \pm 0.95$ & 0.19 \\
50.0 & & \\
500.0 & $5.98 \pm 0.11$ & 1.84 \\
6.0 & $50.16 \pm 0.20$ & 0.40 \\
50.0 & $499.01 \pm 1.91$ & 0.38 \\
500.0 & & \\
Short-term stability (1,2,3hrs) & $6.16 \pm 0.64$ & 10.32 \\
6.0 & $49.41 \pm 0.98$ & 1.99 \\
50.0 & $498.85 \pm 0.63$ & 0.13 \\
\hline 500.0 & & \\
6.0 & $5.89 \pm 0.53$ & 8.96 \\
50.0 & $48.82 \pm 0.41$ & 0.85 \\
500.0 & $495.31 \pm 2.56$ & 0.52 \\
\hline Long term Stability (4.weeks) & &
\end{tabular}

Table 3: Stability study report of Metolazone.

\begin{tabular}{|l|l|l|}
\hline Parameters & Reference & Test \\
\hline $\mathrm{C}_{\max }(\mathrm{ng} . \mathrm{h} / \mathrm{ml})$ & 25.83 & 24.83 \\
\hline $\mathrm{T}_{\max }(\mathrm{hrs})$ & 3.50 & 2.92 \\
\hline $\mathrm{T}_{1 / 2}(\mathrm{hrs})$ & 10.89 & 10.83 \\
\hline $\mathrm{K}_{\mathrm{eli}}(\mathrm{hrs}$ & -1 \\
\hline $\mathrm{AUC}_{0-24}(\mathrm{ng} . \mathrm{h} / \mathrm{ml})$ & 0.07 & 0.06 \\
\hline $\mathrm{AUC}_{0 \text {-inf }}(\mathrm{ng} . \mathrm{h} / \mathrm{ml})$ & 377.34 & 351.12 \\
\hline
\end{tabular}

Table 4:

significantly within the time period under the indicated storage conditions. Long-term stability studies results conclude that metolazone is stable in plasma matrix at least for 30 days when stored at $-20 \pm 2{ }^{\circ} \mathrm{C}$ (Table 3 ).

\section{Pharmacokinetic evaluation}

The Pharmacokinetic evaluation of $C \max$, Tmax, Half Life, $\mathrm{K}$ elimination, $\mathrm{AUC}_{0-\mathrm{t}}$ and $\mathrm{AUC}_{0-\infty}$ these parameters were calculated. The Reference and Test formulation was compared and this result is presented in Table 4.

\section{Conclusion}

SPE of metolazone from plasma was found to be more precise than the other extraction methods. The current method guarantees a high precision, accuracy, recovery and a relatively short analysis time and will be a useful tool in the pharmacokinetic study of metolazone in humans.

\section{References}

1. Brodie RR, Chasseaud LF, Walmsley LM (1981) Determination of the diuretic agent metolazone in plasma by high-performance liquid chromatography. J Chromatogr B 226: 526-532. »CrossRef » PubMed » Google Scholar

2. Farthing D, Fakhry I, Gehr TW, Sica DA (1990) Quantitation of metolazone in urine by high-performance liquid chromatography with fluorescence detection. J Chromatogr B 534: 228-232. »CrossRef » PubMed » Google Scholar

3. Farthing D, Sica DA, Fakhry I, Gehr TW (1994) Novel high-performance liquid chromatographic method using solid-phase on-line elution for determination of metolazone in plasma and whole blood. J Chromatogr B 653: 171-176. »CrossRef » PubMed » Google Scholar

4. Guidance for Industry Bioanalytical Method Validation. U.S (2001) Department of Health and Human Services. Food and Drug Administration, Center for Drug Evaluation and Research, CDER, Rockville, MD, USA. »CrossRef » PubMed » Google Scholar

5. Guidance for Industry, Statistical Approaches in Establishing Bioequivalence U.S (2001) Department of Health and Human Services. Food and Drug Administration, Center for Drug Evaluation and Research, CDER, Rockville, MD, USA. » CrossRef » PubMed » Google Scholar

6. Jadhav V, Mande P, Kadam V (2009) Validation Of Reverse Phase High Performance Liquid Chromatography Method Of Metolazone And Its Determination In Bulk Drug And Pharmaceutical Dosage. J Pharm Res 2: 961 963. » CrossRef » PubMed » Google Scholar

7. Wei G, Xiao S, Liu C (2007) Determination of metolazone in human blood by liquid chromatography with electrospray ionization tandem mass spectrometry. J Chromatogr B 845: 169-173. » CrossRef » PubMed » Google Scholar

8. www.Free wikipedia.com. » CrossRef » PubMed » Google Scholar 